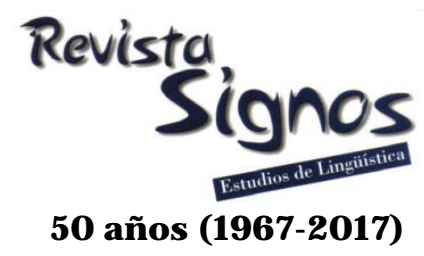

\title{
Interrelación entre gestos y vocalizaciones en funciones comunicativas tempranas: Evidencias desde la lengua vasca ${ }^{*}$
}

\author{
The interrelation of gestures and vocalisation in early \\ communication functions: Evidence from Basque language
}

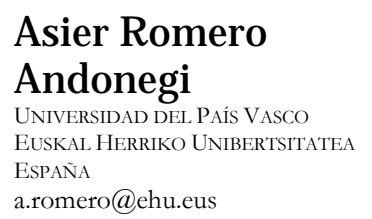

Asier Romero

UNIVERSIDAD DEL PAÍS VASCO

ESPAÑA

a.romero@ehu.eus

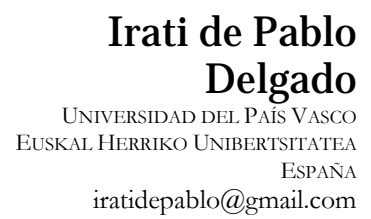

\author{
Aintzane Etxebarria \\ Lejarreta \\ UNIVERSIDAD DEL PAís VASCO \\ EUSKAL HERriko UNIBERTSITATEA \\ ESPAÑA \\ aintzane.etxebarria@ehu.eus
}

Recibido: 27/V/2015 / Aceptado: 11/IV/2016

\section{Resumen}

El objetivo de este estudio longitudinal ha sido el de explorar los patrones combinatorios de gestos y habla desde la etapa del balbuceo reduplicativo a la fase del balbuceo variado o proto-conversacional y la alineación cronológica entre las dos modalidades. El corpus de análisis lo han constituido los actos comunicativos de dos niños vascos de entre $0 ; 9$ y 1;1 con lengua materna euskera. El análisis se ha centrado en el gesto y en la producción vocal sobre un total de 1.260 actos comunicativos extraídos de aproximadamente $6 \mathrm{~h}$. de grabación en casa de los informantes. Los datos extraídos de las grabaciones muestran que (1) desde que se abandona el balbuceo reduplicativo y empieza la etapa prelingüística del balbuceo variado en adelante el gesto comienza a ser producido principalmente en combinación con la producción vocal, más que como un acto únicamente de gestos; (2) la tipología de los gestos en estas combinaciones de gesto y vocalización son principalmente deícticos (apuntando y alcanzando) con una intención comunicativa declarativa; y (3) ya en la etapa del balbuceo proto-conversacional se producen las primeras combinaciones entre el gesto y el discurso, es decir, hay indicios de un patrón de coordinación temporal de ambas modalidades, que consiste en sincronizar el inicio del golpe de gesto deíctico con el 
inicio de la producción vocal. Los resultados avalan la hipótesis de que los niños coordinan temporalmente la combinación gesto-habla ya en el período del balbuceo variado o conversacional.

Palabras Clave: Gestos tempranos, balbuceo, adquisición del lenguaje, combinación de gesto-habla, vasco.

\begin{abstract}
The aim of this longitudinal study is to explore the combinational patterns of gesture and speech from the babbling period to the reduplicative varied babbling and also the temporal alignment between the two modalities. The corpus of the analysis has been built taken into account two Basque at age 9 months and 13 months being Basque their mother tongue. The analysis has focused on the gesture and vocal production of a total of 1.260 communicative acts extracted from approximately $6 \mathrm{hrs}$ of in-home made recording. The extracted data shows that (1) since reduplicative babbling is left behind, the varied babbling pre-linguistic period basically starts to be produced in combination with oral production rather than just as a gesture act; (2) in these early gesture-speech combinations most of the gestures are deictic gestures (pointing and reaching gestures) with a main declarative communicative purpose; (3) when in the period of protoconversational babbling the first combinations of gesture and speech are produced, which means that there are evidences of a temporal coordination pattern between the two mentioned modalities which consists on synchronizing the first deictic gesture beat with the beginning of oral production. These results support the hypothesis that babbling children temporarily coordinate gesture-speech combination since the period of varied or conversational babbling.
\end{abstract}

Key Words: Early gestures, babbling, language development, gesture-speech temporal coordination, Basque.

\title{
INTRODUCCIÓN
}

La combinación de gesto-habla es un rasgo fundamental de la condición humana. Como señala McNeill (1992) en el lenguaje gestual humano las modalidades discursivas son coordinadas no solo en el nivel fonológico sino también en los niveles semánticos y pragmáticos. Así, los niños comienzan a usar combinaciones intencionadas de gesto-habla cerca del final del primer año de vida, unos meses después de haberse iniciado el balbuceo canónico y precediendo a la etapa lingüística de la primera palabra (Butcher \& Goldin-Meadow, 2000; Esteve-Gibert \& Prieto, 2014).

La presencia de estos comportamientos combinados ha sido interpretada como un indicador de comunicación intencional; y aunque existe un acuerdo bastante generalizado en la literatura sobre la edad de aparición de la conducta intencional, se observan discrepancias a la hora de invocar las causas subyacentes que posibilitan la aparición de dicha conducta (Piaget, 1936; Bruner, 1975; Trevarthen, 1979). Algunos autores relacionan los orígenes de la comunicación intencional con el desarrollo cognoscitivo (Piaget, 1936; Bates, Camaioni \& Volterra, 1975). Otros insisten en la 
importancia de la interacción social entre el bebé y el adulto, como hecho determinante en la emergencia de la comunicación intencional y la función esencial que adquieren las formas prelingüísticas en el desarrollo de la intencionalidad comunicativa (Bruner, 1975; Halliday, 1975; Vygotsky, 1979; Kaye, 1982). Finalmente, otras explicaciones se basan en la existencia de una motivación innata en los bebés para comunicarse con el entorno (Trevarthen, 1979; Blomm, 1993). Ahora bien, la investigación sigue siendo necesaria; por ejemplo, para conocer el papel que adquiere la función pragmática en las combinaciones gesto-habla en contextos sociocomunicativos específicos, y su valor potencial predictivo en el posterior desarrollo del lenguaje (Igualada, Bosch \& Prieto, 2015).

Además, hay que señalar que las intenciones comunicativas tempranas pueden ser expresadas tanto por medio de gestos como de vocalizaciones. Así, numerosos investigadores han descrito al gesto y el habla como un sistema integrado en la comunicación, ya que la mayoría de los gestos son producidos junto con el habla, produciéndose una coherencia entre pragmática y semántica, y una sincronización temporal entre la mayor prominencia del gesto con la mayor prominencia en la vocalización (Kendon, 1980; McNeill, 1992; De Ruiter, 2000; Kita, 2000).

La literatura científica sobre la coordinación temporal de los gestos y el discurso proporcionan evidencias que permiten afirmar que el gesto y el habla forman un sistema integrado en el acto comunicativo de los adultos. Además, hay un acuerdo general en la bibliografía para describir que las prominencias entre gesto y habla están temporalmente coordinadas, que la prominencia en el gesto está representada por un golpe de gesto o por la señalización deíctica representada con la máxima extensión del dedo índice, y que la prominencia en el discurso está representada por la sílaba prosódicamente prominente.

Sin embargo, se debe destacar la ausencia de investigaciones centradas en el estudio de la coordinación temporal temprana que se produce entre gestos comunicativos y vocalizaciones tempranas; y es, precisamente, en este contexto en el que se sitúa la presente investigación. Por tanto, partiendo de un corpus longitudinal de dos niños vascos de 0;9 a 1;1 y mediante una metodología observacional sustentada en el enfoque etnográfico no participativo, los objetivos de este estudio se han centrado en la descripción de la combinación gestual con vocalización intencional en el período del balbuceo variado, y la correlación existente entre la producción gestual y las funciones pragmáticas antes de la emergencia de la primera palabra.

\section{Fundamentación teórica}

La combinación de gestos y habla simultánea sirve para proporcionar al adulto información sobre un referente, destacando con ello un determinado elemento de la comunicación. En esta línea, se sitúan diferentes trabajos que han analizado la coordinación simultánea con el habla de gestos deícticos con una función declarativa o 
imperativa, proporcionando evidencias que permiten afirmar que el gesto y el habla forman un sistema integrado en el acto comunicativo, tal y como sucede entre los adultos (Esteve-Gibert, Prieto \& Pons, 2015). En otras palabras, los bebés pueden utilizar intencionalmente estrategias multimodales para marcar una prominencia en sus producciones comunicativas, comportamiento que favorece los procesos de atención conjunta, y refuerza la acción triádica entre el niño, un adulto y un objeto.

La literatura proporciona evidencias suficientes para entender que las habilidades de atención conjunta de los bebés están relacionadas con un desarrollo posterior del lenguaje (Bosh, 2004). Además, los resultados de estas investigaciones proporcionan evidencias indirectas acerca de la posible relación entre la capacidad comunicativa multimodal de un bebé (para comunicarse e influir en la atención de un adulto con relación a un determinado objeto) con el posterior desarrollo de habilidades lingüísticas (Tomasello \& Farrar, 1986; Tomasello, 1988; Feldman \& Reznick, 1996; Sacks, 1997; Mundy \& Gomes, 1998; Rivero, 2003; Papaeliou \& Trevarthen, 2006; Rochat, 2007; Miller \& Lossia, 2013).

Los estudios que abordan las habilidades de comunicación temprana de los bebés, generalmente, se han centrado en el análisis por separado de gestos y habla, y no como una circunstancia de estudio conjunto (Fernández, 2009; Romero, Etxebarria, Gaminde \& Garay, 2015). Por ejemplo, la capacidad de utilizar gestos deícticos ha sido considerada como una estrategia no verbal clara que emplea el niño para establecer una relación interactiva con el adulto, desempeñando un papel fundamental en la emergencia de la función referencial/declarativa; y, por tanto, como un buen predictor en la emergencia del lenguaje verbal (Triadó, 1984; Tomasello, Carpenter \& Liszkowski, 2007). Otra serie de trabajos han relacionado los gestos representacionales o icónicos con la aparición de las primeras palabras. Estos gestos difieren de los gestos deícticos en la presencia de un referente exacto. Por tanto, se interpretan como movimientos convencionales que se asocian con significados relativamente estables en situaciones comunicativas diferentes (Bates et al., 1975; Volterra, Camaioni, Benigni \& Bates, 1981; Shore, Bates, Bretherton, Beeghly \& O’Connell, 1990; Caselli, Rinaldi, Stefanini \& Volterra, 2012). Por otro lado, la literatura sobre el desarrollo del habla también ha documentado que las medidas acústicas en las vocalizaciones tempranas de los bebés varían dependiendo de su intencionalidad comunicativa (Esteve-Gibert \& Prieto, 2014). Asimismo, estudios con niños han demostrado que se puede predecir el inicio del desarrollo gramatical en el uso particular de combinaciones de algunas modalidades gestuales junto con el habla (Iverson \& Goldin-Meadow, 2005; Rowe \& Goldin-Meadow, 2009).

Los estudios sobre la coordinación temporal de los gestos y el discurso proporcionan evidencias que permiten afirmar que el gesto y el habla forman un sistema integrado en el acto comunicativo de los adultos. En este contexto, se ha 
demostrado que la parte más prominente del gesto coincide con la parte acústicamente más prominente del discurso (Kendon, 1980). Ahora bien, este consenso se vuelve más heterogéneo en lo que respecta a la localización en el discurso del punto en el que se produce la coincidencia prominente con el gesto (Butterworth \& Beattie, 1978; Levelt, Richardson \& La Heij, 1985; Nobe, 1996; De Ruiter, 1998; Krahmer \& Swerts, 2007; Loehr, 2007; Ferré, 2010; Leonard \& Cummins, 2010; Roustan \& Dohen, 2010; Bergmann, Aksu \& Kopp, 2011; Esteve-Gibert \& Prieto, 2013). Por tanto, tomando en conjunto los resultados de estos trabajos, hay un acuerdo general en la bibliografía para describir que (a) las prominencias entre gesto y habla están temporalmente coordinadas, (b) la prominencia en el gesto está representada por la señalización deíctica descrita con la máxima extensión del dedo índice, y (c) la prominencia en el discurso está representada por la sílaba prosódicamente prominente.

Lógicamente, atendiendo a lo descrito hay una pregunta obvia: ¿hay una suficiente coordinación entre gesto y habla en los bebés como para constituir un sistema integrado, tal y como sucede en el acto comunicativo de los adultos? A este respecto, Iverson (2010: 258) afirma:

"(...) one possibility is that the origins of speech/gesture coordinations lie in hand-mouth linkages that are observed in the everyday sensorimotor activity of very young infants who do not yet use the hand or mouth to communicate meaning. In other words, it is the initial sensorimotor linkages of these systems that form the bases for their later cognitive interdependence".

La coordinación entre habla y gestos tendría sus orígenes evolutivos en los vínculos tempranos mano-boca ${ }^{2}$. Este autor se basa para su argumentación en la teoría de los sistemas dinámicos de control-motor para mostrar cómo dos sistemas mutuamente activos pueden influir y arrastrar el uno al otro de forma sincronizada (Iverson \& Thelen, 1999). Además, para esta última investigadora, el organismo infantil debería ser considerado como un sistema dinámico con unas peculiaridades definidas (Thelen, 1992). Por tanto, atendiendo a los estudios más recientes centrados en la rítmica motriz, se puede señalar que estos movimientos rítmicos vocálicomotrices pueden llegar a ser marcadores predictivos en la coordinación entre el gesto y las modalidades del discurso (Ejiri \& Masataka, 2001; Lew \& Butterworth, 1997). Sin embargo, hay que señalar la ausencia de investigaciones centradas en el estudio de la coordinación temporal temprana que se produce entre gestos comunicativos y vocalizaciones tempranas. Para nuestro conocimiento, solo hay dos trabajos que abordan esta cuestión. Por una parte, el de Butcher y Goldin-Meadow (2000), quienes sugieren que no se produce hasta el comienzo del período de dos palabras cuando los niños integran el gesto y el discurso como un solo sistema para comunicarse intencionadamente; y por otra parte, el trabajo de Esteve-Gibert y Prieto (2014) que sigue la línea básica de investigación del trabajo de Butcher y Goldin-Meadow (2000) 
añadiendo dos aspectos innovadores: analiza las combinaciones de gesto-vocalización ya en la etapa del balbuceo, y estudia la prominencia prosódica en el gesto.

A tenor de lo expuesto, el estudio que presentamos tiene un triple objetivo. En primer lugar, describir cuándo y cómo los niños combinan gestos con vocalización en el período del balbuceo variado con una intención comunicativa. Para cumplir este objetivo, el estudio ha analizado el repertorio gestual en combinación con vocalizaciones y con una conducta intencional producidas por dos niños.

En segundo lugar, se ha investigado con precisión la sincronización temporal temprana del gesto con la vocalización. Para este objetivo, se ha analizado la distancia temporal entre el inicio del gesto y la aparición de la vocalización. A este respecto, nuestra hipótesis es que encuentran evidencias de una coordinación temporal en las combinaciones de gesto-habla, ya en el período del balbuceo variado o conversacional.

En tercer lugar, se ha analizado la correspondencia entre las funciones comunicativas intencionales de las vocalizaciones y su correspondencia gestual antes de la emergencia de la primera palabra. Para este objetivo se ha utilizado una clasificación de funciones comunicativas en la que se adaptan algunos elementos de taxonomías como la de Bates et al. (1975), la de Sarriá (1991) y la de Karousou (2003). En este sentido, la hipótesis nula planteada era que la tipología gestual deíctica con una motivación imperativa no se coordinaba temporalmente en la producción vocálica.

\section{Corpus y metodología}

\subsection{Participantes}

En este análisis longitudinal, los sujetos de estudio son dos niños vascos con lengua materna euskera, e identificándose en el estudio como MBR [masc.] y ALL [masc.]. Así, entre los meses 0;9 y 1;1 se analizó el gesto de los niños y sus combinaciones con la producción del habla (ver Tabla 1). Los niños pertenecen a hogares de clase media de un pequeño pueblo de la costa vizcaína, Bermeo, situado a 30 kilómetros al nordeste de Bilbao. En este contexto, los padres de los niños participantes hablan exclusivamente en vasco con los niños. Además, se dan dos parámetros más a tener en cuenta: los informantes eran, en el momento de las grabaciones, hijos únicos; y todavía no habían sido escolarizados en el primer ciclo de Educación Infantil. 
Tabla 1. Datos de los informantes.

\begin{tabular}{|l|l|l|l|l|}
\hline $\begin{array}{l}\text { Siglas que } \\
\text { identifican al } \\
\text { informante }\end{array}$ & $\begin{array}{l}\text { Edad de la } \\
\text { primera } \\
\text { grabación }\end{array}$ & $\begin{array}{l}\text { Edad de la } \\
\text { última } \\
\text { grabación }\end{array}$ & $\begin{array}{l}\text { Número de } \\
\text { grabaciones en } \\
\text { las que participa }\end{array}$ & $\begin{array}{l}\text { Duración de } \\
\text { todas las } \\
\text { grabaciones del } \\
\text { informante }\end{array}$ \\
\hline MBR [masc.] & $0 ; 9.2$ & $1 ; 1.19$ & 6 & 3h. 16' 26" \\
\hline ALL [masc.] & $0 ; 9.20$ & $1 ; 1.22$ & 6 & 3h. 34' 23'” \\
\hline
\end{tabular}

\subsection{Procedimiento}

Hay que señalar que en ningún caso se ha fijado con anterioridad a las sesiones un estricto patrón organizativo de las actividades a realizar. Por tanto, mediante esta actitud flexible se buscaba establecer una interacción dinámica, dialogante, abierta y, en cierto modo, libre en la interactuación con los sujetos del corpus. Las sesiones de grabación (semanal o quincenal) tuvieron lugar cronológicamente desde que los niños tenían 0;9 hasta que tuvieron 1;1. Las sesiones se registraron en vídeo en las casas de los sujetos mediante una metodología observacional sustentada en el enfoque etnográfico no participativo. La duración de las mismas fue de 20 y 45 min. aproximadamente, dependiendo de la atención que mostraran los niños. Las grabaciones se realizaron utilizando una cámara ZOOM modelo Q3HD.

\subsection{Codificación}

La producción gestual y vocal fue registrada cada dos semanas aproximadamente, durante los cuatro meses de grabación, con un total de 12 sesiones y un cómputo total de 6 horas de grabación, aproximadamente. En la Tabla 2 se referencia al respecto información del corpus (participante, edad y duración de la grabación). Asimismo, hay que señalar que este rango de edad fue seleccionado, precisamente, por tratarse del periodo clave en el que se producen los primeros actos comunicativos no verbales intencionados mediante el gesto, y su transición desde el balbuceo canónico al período del balbuceo variado o conversacional.

Tabla 2. Datos de las grabaciones.

\begin{tabular}{|c|c|c|c|}
\hline Grabación & Participante & Edad & Duración \\
\hline MBR_1 & MBR & $0 ; 9.2$ & 20’32"' \\
\hline MBR_2 & MBR & $0 ; 10.1$ & $38^{\prime} 46^{\prime \prime}$ \\
\hline MBR_3 & MBR & $0 ; 10.28$ & $43^{\prime} 54^{\prime \prime}$ \\
\hline MBR_4 & MBR & $0 ; 11.16$ & 41'12"' \\
\hline MBR_5 & MBR & $1 ; 0.22$ & 12'34"' \\
\hline MBR_6 & MBR & $1 ; 1.19$ & 41'39"' \\
\hline ALL_1 & ALL & $0 ; 9.20$ & $38^{\prime} 25^{\prime \prime}$ \\
\hline ALL_2 & ALL & $0 ; 10.21$ & 45’12”' \\
\hline ALL_3 & ALL & $0 ; 11.14$ & $37^{\prime} 43^{\prime \prime}$ \\
\hline ALL_4 & ALL & $1 ; 0.6$ & 41’02"' \\
\hline ALL_5 & ALL & $1 ; 0.29$ & 22'34"' \\
\hline ALL_6 & ALL & $1 ; 1.22$ & $30 ’ 53^{\prime \prime}$ \\
\hline
\end{tabular}


Por tanto, el rango de edad incluido en este estudio comienza en una etapa anterior a la que se analiza en el estudio de Esteve-Gilbert y Prieto (2014) o al investigado en el trabajo de Butcher y Goldin-Meadow (2000), que sitúan el arranque de su investigación en el periodo prelingüístico del balbuceo variado o del lingüístico de una sola palabra, respectivamente. A tenor de lo registrado en las sesiones de grabación y, a diferencia de lo que ocurre en otros estudios, en el estudio que se presenta no se constataron producciones de palabra o formas 'fonéticamente consistentes' por ninguno de los dos niños.

Todos los actos comunicativos (visuales y/o vocales) producidos por los niños fueron identificados y localizados en las grabaciones, utilizando el software de transcripción multimodal ELAN (Lausberg \& Sloetjes, 2009). El análisis comprendió cinco momentos principales, codificados y analizados mediante seis líneas de transcripción usando ELAN (Figura 1) ${ }^{3}$ : acto comunicativo (communicative act), tipo de gesto (gesture type), motivación del gesto (gesture motive), fases del gesto (gesture phases), extensión máxima del índice (apex) y vocalización (speech). Así mismo, siguiendo los criterios establecidos por Goldin-Meadow (2005), se han excluido de la base de datos todos los movimientos de la mano que implicaban la manipulación directa de un objeto o eran parte de un juego ritualizado. Así, las aproximadamente 6 horas de grabación fueron segmentadas en 1260 actos comunicativos, de los cuales 723 se clasificaron como solo vocalización (speech-only), 327 solo gesto (gesture-only) y 210 como combinación de gesto más vocalización (gesture-speech combination).

Con el objetivo de comprobar la fiabilidad de la ubicación de los actos comunicativos con las combinaciones anteriormente descritas, se utilizó el procedimiento de acuerdo inter-jueces con dos evaluadores externos e independientes y mediante el cálculo del índice Kappa (Cohen, 1960). El coeficiente de Kappa se utilizó en un subconjunto del 20\% de los datos (252 casos), dando como resultado un estadístico Kappa de 0,787, lo que indica que hubo un acuerdo sustancial entre codificadores con respecto a la identificación y localización de los actos comunicativos. En cuanto a la clasificación de los actos comunicativos en una de las tres categorías, el estadístico Kappa ha sido de 0,741, considerado también como un índice de acuerdo excelente.

En primer lugar, se ha identificado y codificado el acto comunicativo (communicative act) con las etiquetas solo habla (speech-only), solo gesto (gesture-only) o la combinación gesto más habla (gesture-speech combination) (ver línea 1 en Figura 1). La acción del niño fue considerada como conducta intencionada comunicativa cuando se observaron los siguientes indicios, (a) el niño orienta su mirada hacia el adulto interlocutor, mientras vocaliza y/o gesticula; (b) el niño proporciona al adulto un tiempo para intervenir después de haber vocalizado y/o gesticulado; (c) el adulto se siente interpelado por la 
vocalización y/o gesticulación infantil; y (d) el niño manifiesta su frustración cuando la reacción del interlocutor no le satisface.

En segundo lugar, se ha determinado el tipo de gesto (gesture type) utilizando las categorías establecidas en la literatura y que definen al gesto como una forma de comunicación no verbal ejecutada con alguna parte del cuerpo y producida por el movimiento de las articulaciones, músculos de brazos, manos o cabeza (Ekman \& Friesen, 1969; Triadó, 1984; Iverson, Tencer, Lany \& Goldin-Meadow, 2000; Capone \& McGregor, 2004; Blake, Vitale, Osborne \& Olshansky, 2005) (ver línea 2 en Figura 1): gesto deíctico (pointing gesture), el niño extiende el brazo para atraer la atención del interlocutor sobre un objeto; gesto de alcanzar (reaching gesture), se trata de un tipo de gesto deíctico producido cuando el niño extiende el brazo y abre la mano hacia un objeto para dirigir la atención del interlocutor; gesto convencional (conventional gesture), se trata de acciones rituales del niño moviendo la cabeza con la significación de afirmación o negación, saludo, aplauso, etc; gesto emotivo (emotive gesture), se trata de la expresión de un estado emocional; gesto simbólico (symbolic gesture), cuando el niño coge, por ejemplo, un bloque de madera y lo emplea como si fuera un coche, o se lleva la mano a la oreja para referirse al teléfono, etc. (ver Tabla 3)

Tabla 3. Sumario de tipos de gestos acompañado de imágenes.

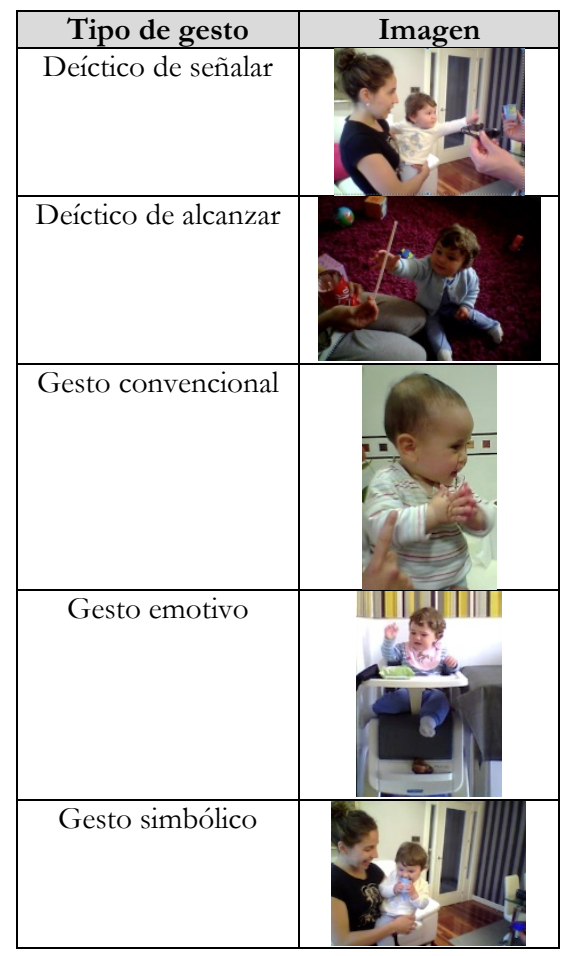


A continuación, se han clasificado los gestos en cuanto a su motivación o intencionalidad (ver Tabla 4). La motivación del gesto fue anotada con el objeto de investigar las influencias potenciales de este factor sobre la alineación temporal de gesto y vocalización. A este respecto, se tuvieron en cuenta dos categorías en la anotación, imperativa o declarativa: imperativa (imperative) los niños realizan este gesto deíctico indicando que quieren coger algún objeto y declarativo (declarative), cuando el gesto del niño tiene por objeto dirigir la atención del interlocutor hacia un objeto o acontecimiento que le produce curiosidad o asombro (ver línea 3 en Figura 1). En la literatura científica ya se señala esta dicotomía como fundamental para discernir el comienzo de la comunicación intencional (Bates et al., 1979; Liszkowski, 2007; Tomasello et al., 2007; Esteve-Gibert \& Prieto, 2014).

Tabla 4. Correspondencia entre tipología y motivación gestual acompañado de imágenes.

\begin{tabular}{|c|l|c|}
\hline Tipo de gesto & Motivación & Imagen \\
\hline Deíctico de señalar & declarativa & \\
\hline Deíctico de alcanzar & Imperativa & \\
\hline
\end{tabular}

Con el objetivo de comprobar la fiabilidad de la codificación del gesto, se utilizó el valor estadístico Kappa de Cohem con los dos evaluadores independientes que participaron anteriormente. En este caso, el coeficiente de Kappa se utilizó en un subconjunto arbitrario del 20\% de los datos (42 casos), en términos de tipología de gesto y motivación del gesto. Para la tipología gestual (señalar, alcanzar, convencional, emotivo e icónico) el estadístico Kappa ha sido de 0,923, sugiriendo un acuerdo casi perfecto. Para la motivación gestual (imperativo o declarativo), el estadístico Kappa ha sido de 0,782 , mostrando de nuevo un alto grado de acuerdo entre codificadores.

En cuarto lugar, se codificaron las fases gestuales (gesture phases) siguiendo el estudio de Kendon (2004) (ver línea 4 en Figura 1): (a) fase de preparación (preparation) el brazo se mueve desde la fase de descanso hasta el inicio del gesto de señalar/alcanzar, (b) fase de golpe gestual (stroke) cuando la expresión del gesto logra su objetivo, sea cual sea, y en la que la dinámica de movimiento logra una clara correspondencia entre esfuerzo y forma ${ }^{4}$, (c) fase de retracción (retraction) el brazo desde esa fase de golpe regresa a su posición de descanso.

Asimismo, se ha codificado en una quinta línea el momento cumbre del ápice gestual (apex), es decir, la duración de esta altura máxima que alcanza la mano con su dedo índice señalando o pidiendo un objeto. Sería el punto específico dentro del intervalo de recorrido en el que se produce esta circunstancia (ver línea 5 en Figura 1). 


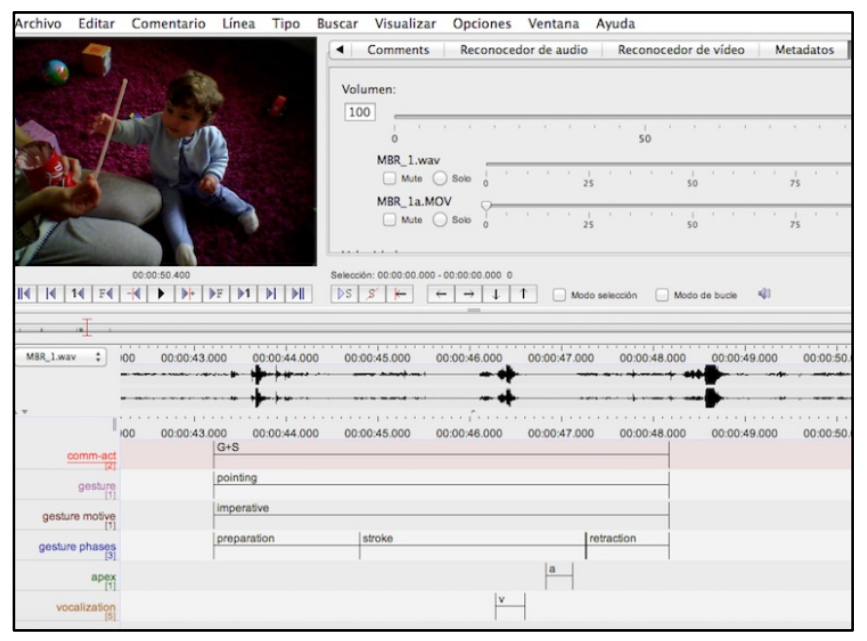

Figura 1. Imágenes de ELAN con las líneas de anotación.

Con el objetivo de localizar dentro de la fase de golpe gestual (stroke), el momento en el que se producía la cumbre de ápice gestual (apex), se recurrió a la opción que presenta ELAN de visionar el vídeo fotograma por fotograma en cadencias de $2 \mathrm{~ms}$. Así, se señaló diferenciando en la anotación entre el momento en el que el ápice gestual alcanzaba la mayor extensión, de la fase en la que se realizaba el golpe gestual ${ }^{5}$.

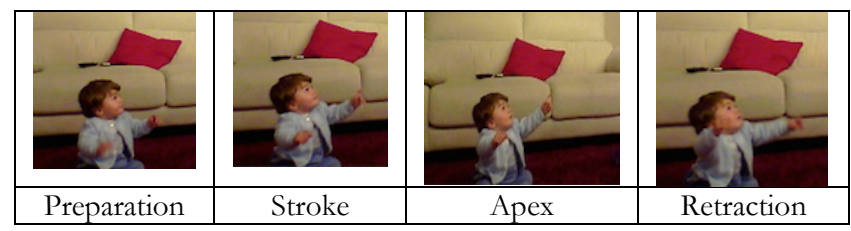

Figura 2. Fases del gesto utilizando las opciones de anotación de ELAN.

Finalmente, en una sexta línea se ha codificado la vocalización del niño (vocalization). Entendemos por vocalizaciones aquellas "producciones tempranas interpretables por los padres, con o sin contenido segmental, en las que el niño produce grupos prosódicos de duración variable" (López Ornat \& Karousou, 2005: 1). No se trata aún, pues, de una unidad léxica definida con contenido fonológico convencional sino, más bien, de un juego vocal o sonoro ${ }^{6}$.

Desde un punto de vista metodológico, se analizaron las vocalizaciones atendiendo al sistema de codificación planteado por Karousou, en lo concerniente a la interpretación de la función de las vocalizaciones comunicativas (Karousou, 2003), estableciéndose las siguientes categorías de codificación: función declarativa (declarative), función imperativa (imperative), función expresiva (emotive), función mímica (mimic), función guía de acción (action guide) y la función fática (fatica), (ver línea 6 en Figura 1). 
Esta categoría descrita incluye cualquier vocalización producida por el niño, excepto los sonidos puramente 'vegetativos', la risa, los gritos y el llanto. Se descartaron asimismo, las producciones emitidas por los niños teniendo un objeto en la boca (por ejemplo el chupete). Por otra parte, desde un punto de vista pragmático tan solo se codificaron las vocalizaciones producidas como un acto comunicativo intencional (Goldstein \& Pollock, 2000). En cuanto a la delimitación exacta de la vocalización, se utilizó el criterio de codificar una vocalización como expresión independiente cuando había una separación superior a los 300 ms. (Oller, Wieman, Doyle \& Ross, 1976; Igualada et al., 2015). Al igual que en los casos anteriores, con el objetivo de comprobar la fiabilidad de la codificación de la función de la vocalización, se utilizó el valor estadístico Kappa de Cohem con los dos evaluadores independientes que participaron anteriormente. En este caso, el coeficiente de Kappa se utilizó en un subconjunto arbitrario del 20\% de los datos (144 casos), dando como resultado un estadístico Kappa de 0,846, lo que indica que hubo un acuerdo sustancial entre codificadores con respecto a la identificación de la función vocálica.

\section{Resultados}

El objetivo principal de esta investigación es analizar el desarrollo temprano del gesto, su tipología, sus fases y su posible combinación con la producción vocálica. Por tanto, los resultados se presentan en tres secciones principales, atendiendo a cada uno de los objetivos establecidos.

\section{1. ¿Cómo se produce la combinación entre gesto y habla en el periodo cronológico analizado?}

En primer lugar, examinaremos el momento en el que los dos niños comienzan a combinar gestos con vocalización a lo largo de este periodo cronológico señalado. En el Gráfico 1 aparece descrita la distribución (expresada en porcentajes) de todos los actos comunicativos analizados: 'solo gesto', 'solo vocalización' y 'gesto más vocalización'; teniendo en cuenta también la variable de la edad. Además, como se puede observar en este gráfico, todos los actos comunicativos contienen gestos; ahora bien, a partir del subgrupo 1:0, la proporción de combinación 'gesto-vocalización' es superior a la proporción 'solo gesto'. Para probar si había una significación estadística en la variación entre la proporción ‘solo gesto’ y combinación 'gesto-vocalización' en la relación con la edad, se utilizó la prueba Chi-cuadrado de independencia. Los resultados mostraron que la proporción 'solo gesto' en la combinación de 'gestovocalización' era estadísticamente significativa para el subgrupo $0 ; 9\left(\chi^{2}(1, N=99)=\right.$ $32.818, p<.001)$ y para el subgrupo $0 ; 10\left(\chi^{2}(1, N=122)=20.492, p<.001\right)$ pero no para los subgrupos $0 ; 11\left(\chi^{2}(1, N=159)=5.289, p=.222\right)$, ni para $1 ; 0\left(\chi^{2}(1, N=\right.$ $109)=1.110, p=.293)$ ni para $1 ; 1\left(\chi^{2}(1, N=48)=1.333, p=.249\right)$. Por tanto, estos resultados indican que en los subgrupos 0;9 y 0;10 los dos niños producen la mayor parte de sus gestos sin acompañamiento vocálico pero con una combinación 
proporcional en relación con la variable 'gesto-vocalización' estadísticamente significativa; y que a partir del undécimo mes (subgrupo 0;11) esta tendencia se invierte siendo la proporción mayoritaria la que resulta de la combinación entre gesto y vocalización, aunque sin resultados estadísticamente significativos en lo concerniente a la combinación de las dos variables planteadas.

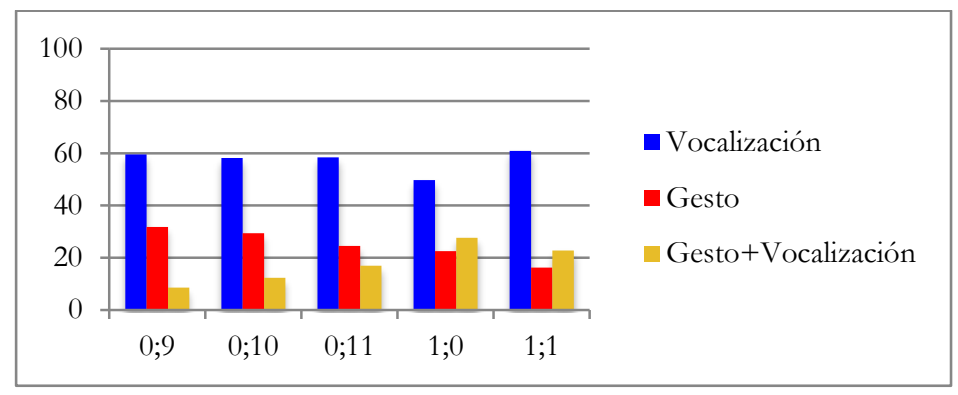

Gráfico 1. Ratio de porcentajes en la distribución de todos los actos comunicativos en las categorías: 'Solo gesto', 'solo vocalización' y 'gesto más vocalización'.

En relación con la segunda cuestión planteada, es decir, qué tipo de gestos producen los niños en las primeras combinaciones 'gesto-vocalización', la Tabla 5 muestra la distribución correspondiente a la tipología gestual (expresada en números absolutos y porcentajes) para todos los subgrupos de edad en la combinación 'gestovocalización'. Los resultados muestran que los gestos deícticos fueron la tipología gestual predominante en los todos los subgrupos de edad a excepción del subgrupo 0;9. La distribución de los porcentajes sería la que se presenta a continuación. En el subgrupo 0;9 el 33,32\% lo constituirían los gestos deícticos (dividido en un 14,28\% para el gesto deíctico de señalar y un 19,04\% para el gesto deíctico de alcanzar), en tanto que la producción del gesto emotivo constituye el 38,9\%. En el subgrupo 0;10 la proporción se invierte, así el 49,99\% lo constituirían los gestos deícticos (dividido en un 30,55\% para el gesto deíctico de señalar y un 19,44\% para el gesto deíctico de alcanzar), mientras que la producción del gesto emotivo constituye el 22,22\%. En el subgrupo 0;11, aunque la producción de gestos convencionales aumenta hasta el $16,92 \%$, la producción de gestos deícticos supera a cualquier tipología gestual, así el $61,53 \%$ lo constituirían los gestos deícticos (dividido en un 35,38\% para el gesto deíctico de señalar y un 26,15\% para el gesto deíctico de alcanzar), constituyendo la producción del gesto emotivo el mínimo de la serie porcentual en relación con los otros subgrupos con tan solo el 9,23\%. En el subgrupo 1;0 los gestos deícticos alcanzan su máximo porcentual en relación a otros subgrupos anteriores, llegando al $71,66 \%$ (dividido en un $41,66 \%$ para el gesto deíctico de señalar y un $30 \%$ para el gesto deíctico de alcanzar), en tanto que la producción del gesto emotivo constituye tan solo el 10\%. Finalmente, el subgrupo 1;1 presenta también una clara presencia porcentual del gesto deíctico frente a otro tipo de gesto, aunque con la particularidad de que en este subgrupo se produce un aumento en la producción del gesto convencional y emotivo. Así, en términos porcentuales la producción del gesto 
deíctico estaría en un 53,56\% (dividido en un 32,14\% para el gesto deíctico de señalar y un $21,42 \%$ para el gesto deíctico de alcanzar), siendo tan solo de un 7,14\% la producción del gesto emotivo.

Tabla 5. Número total y porcentual del tipo gestual en la combinación gesto más vocalización.

\begin{tabular}{|c|c|c|c|c|c|c|c|c|c|c|}
\hline \multirow{2}{*}{ Edad } & \multicolumn{2}{|c|}{ Señalar } & \multicolumn{2}{|c|}{ Alcanzar } & \multicolumn{2}{c|}{ Convencional } & \multicolumn{2}{|c|}{ Emotivo } & \multicolumn{2}{|c|}{ Simbólico } \\
\cline { 2 - 12 } & $N$ & $\%$ & $N$ & $\%$ & $N$ & $\%$ & $N$ & $\%$ & $N$ & $\%$ \\
\hline $0 ; 9$ & 3 & 14,28 & 4 & 19,04 & 3 & 14,28 & 8 & 38,09 & 3 & 14,28 \\
\hline $0 ; 10$ & 11 & 30,55 & 7 & 19,44 & 5 & 13,88 & 8 & 22,22 & 5 & 13,88 \\
\hline $0 ; 11$ & 23 & 35,38 & 17 & 26,15 & 11 & 16,92 & 6 & 9,23 & 8 & 12,30 \\
\hline $1 ; 0$ & 25 & 41,66 & 18 & 30 & 9 & 15 & 6 & 10 & 2 & 3,33 \\
\hline $1 ; 1$ & 9 & 32,14 & 6 & 21,42 & 6 & 21,42 & 5 & 17,85 & 2 & 7,14 \\
\hline
\end{tabular}

En cuanto a la motivación gestual, hay que subrayar que la mayor parte de los gestos deícticos tienen una motivación declarativa frente a la motivación imperativa en todos los subgrupos de edad (ver Gráfico 2). Ahora bien, si realizamos un desglose, se observa con interés cómo la motivación imperativa se transmite en la mayor parte de las veces por medio del gesto deíctico de alcanzar, mientras que para la motivación declarativa se empleó el gesto deíctico de señalar (ver Gráfico 3).

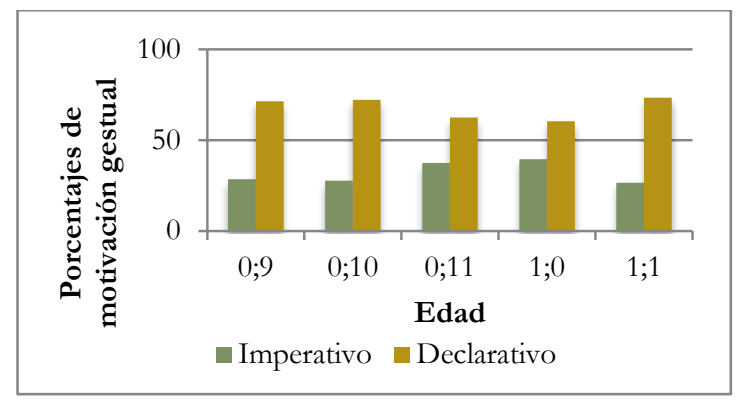

Gráfico 2. Ratio de distribución de porcentajes según la motivación gestual.
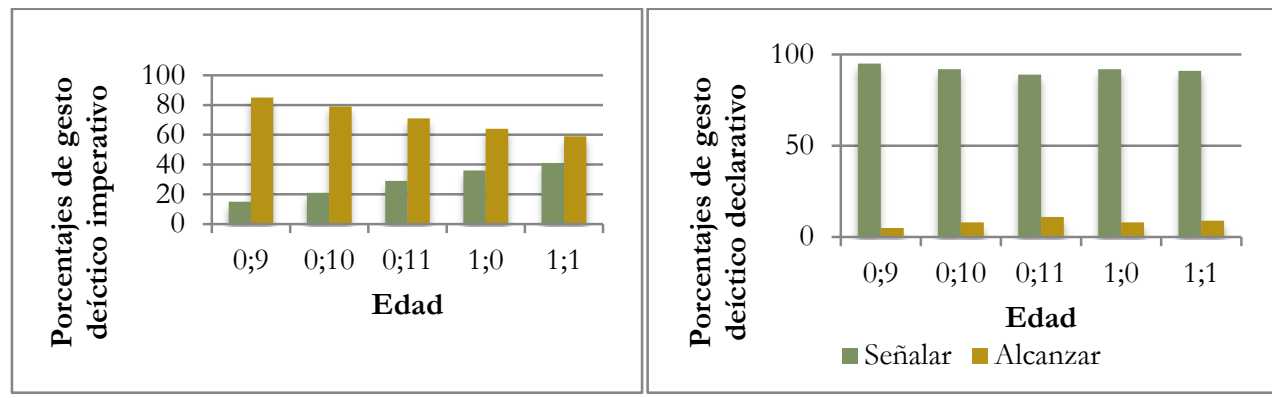

Gráfico 3. Ratio de distribución del tipo de gesto según la motivación imperativa o declarativa.

Por otra parte, se analizó también la posible influencia de la motivación gestual en la duración del gesto y, por consiguiente, en la repercusión que podría tener este factor 
en las combinaciones tempranas de gesto más vocalización. La hipótesis nula planteada en la introducción era que la tipología gestual deíctica con una motivación imperativa no se coordinaba temporalmente en la producción vocálica. Sin embargo, a tenor del análisis estadístico realizado, hay que señalar que dicha influencia sí se produjo. Específicamente, se utilizó el Modelo Lineal Mixto (LMM en inglés; West, Welch \& Galecki, 2007) teniendo en cuenta que la duración del golpe gestual era analizado como variante dependiente, la motivación gestual (en sus dos niveles: imperativa o declarativa) como factor fijo y el sujeto como un factor arbitrario. Los resultados revelaron un efecto de influencia de la motivación gestual sobre la duración del golpe gestual $(F(1,126)=165.491, p<.001)$. Por tanto, la hipótesis alternativa considerada, fue la necesidad de que el gesto deíctico de señalar y alcanzar con una motivación imperativa, necesitaba de más tiempo para su realización y, por tanto, se podría coordinar de una manera más adecuada con la vocalización.

\section{2. ¿Cómo se coordinan temporalmente el gesto y la vocalización teniendo en cuenta la variable temporal establecida?}

En los estudios con adultos de la coordinación temporal entre gesto y habla, se han identificado dos niveles diferentes en la sincronización temporal entre gesto deíctico y vocalización: (1) la relación temporal entre el inicio del gesto y el inicio de la vocalización con el objetivo de comparar los resultados del estudio con la literatura existente, que sugiere que el inicio del gesto siempre precede al inicio del discurso (Levelt et al., 1985); (2) la coordinación temporal entre el inicio del golpe del gesto y el inicio de la vocalización, ya que en estudios centrados en adultos se produce una coordinación entre el golpe gestual y el inicio del discurso (Bergmann et al., 2011).

Todos los análisis estadísticos de esta sección fueron realizados mediante la aplicación del Modelo Lineal Mixto (LMM en inglés; West et al., 2007) usando SPSS 22.07. West ya señala que los modelos lineales mixtos son los más apropiados para analizar datos de carácter longitudinal (correlacionados, incompletos y con intervalos entre observaciones no constantes) ${ }^{8}$.

En primer lugar, se analizó la coordinación temporal entre el inicio del gesto y el inicio de la vocalización. La distancia temporal entre el inicio de la producción vocálica y la aparición del gesto fue la variable dependiente, la edad constituyó el factor fijo con cinco niveles, y el sujeto se analizó como factor aleatorio. El análisis reveló un efecto estadísticamente significativo en el factor fijo (la edad), en la distancia entre el inicio del gesto y en la aparición de la producción vocal $(F(4,3611.12)=270.92$, p < .001) . Con el objeto de determinar en qué pares de subgrupos de edad se podía dar esta significación estadística entre el inicio del gesto y el inicio de la producción vocal, se utilizó el procedimiento de la Diferencia Significativa Mínima (DSM) de Fisher ${ }^{9}$. Los resultados reflejaron esta variación significativa entre subgrupos de edad: entre $0 ; 9 \mathrm{y}$ 
$0 ; 10(\mathrm{p}<.001)$, entre $0 ; 9$ y $0 ; 11(\mathrm{p}<.05)$, entre $0: 9$ y $1 ; 0(\mathrm{p}<.001)$, entre $0 ; 9$ y $1 ; 1$ ( $\mathrm{p}$ $<.001$ ), entre $0 ; 10$ y $0 ; 11$ ( $\mathrm{p}<.001)$, entre $0 ; 10$ y $1 ; 0(\mathrm{p}<.001)$, entre $0 ; 10$ y $1 ; 1$ ( $\mathrm{p}<$ $.001)$, entre $0 ; 11$ y $1 ; 0$ ( $\mathrm{p}<.001)$, entre $0 ; 11$ y 1;1 ( $\mathrm{p}<.01)$, entre $1 ; 0$ y 1;1 ( $<<.001)$. En el Gráfico 4, se demuestra que la aparición del gesto precede a la aparición de la vocalización en todas las edades, y que la tendencia conforme evoluciona el subgrupo de la edad, es la de disminuir esta distancia entre estos dos puntos de producción multimodal.

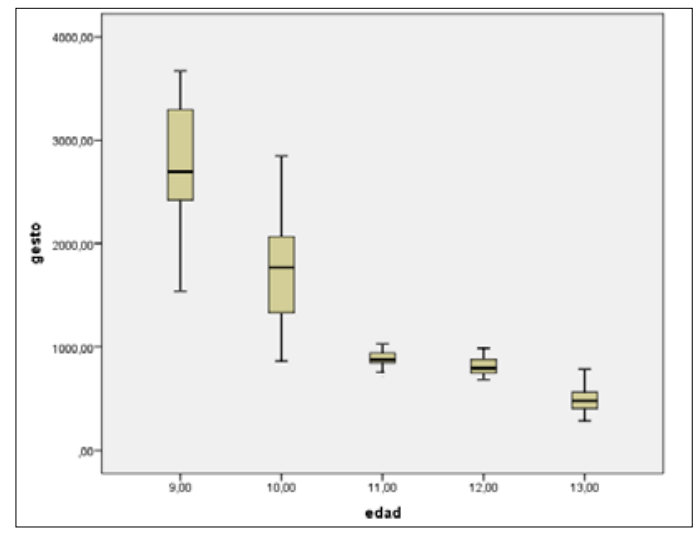

Gráfico 4. Distancia temporal en milisegundos entre el inicio de gesto e inicio de la producción vocal.

En segundo lugar, se analizó la coordinación temporal entre el inicio del golpe del gesto deíctico y el inicio de la vocalización. La distancia temporal entre el inicio del golpe de gesto y la producción vocálica fue la variable dependiente, la edad constituyó el factor fijo con cinco niveles, y el sujeto se analizó como factor aleatorio. El análisis estadístico indicó que la edad tiene un efecto sobre esta distancia $(F(4,2226.512)=$ 333.46, $\mathrm{p}<.001$ ). Con el objeto de determinar en qué pares de subgrupos de edad se podía dar esta significación estadística entre el inicio del gesto y el inicio de la producción vocal, se utilizó el procedimiento estadístico anteriormente descrito. Los resultados reflejaron esta variación significativa entre subgrupos de edad: entre $0 ; 9$ y $0 ; 10(p<.001)$, entre $0 ; 9$ y $0 ; 11(p<.001)$, entre $0: 9$ y $1 ; 0(p<.001)$, entre $0 ; 9$ y $1 ; 1$ ( $p$ $<.001$ ), entre $0 ; 10$ y $0 ; 11$ ( $\mathrm{p}<.001)$, entre $0 ; 10$ y $1 ; 0(\mathrm{p}<.05)$, entre $0 ; 10$ y 1;1 $(\mathrm{p}<$ $.001)$, entre $0 ; 11$ y 1;0 ( $\mathrm{p}<.001)$, entre $0 ; 11$ y $1 ; 1$ ( $\mathrm{p}<.001)$, entre 1;0 y 1;1 ( $<<.001)$. En el Gráfico 5 se observa esta alineación temporal entre ambas modalidades de producción a través de los subgrupos de edad, mostrando ya para el subgrupo 1;1 una correspondencia casi coexistente; y que coincide - tal y como se señalan en estudios precedentes- con el periodo de producción lingüística de una palabra. 


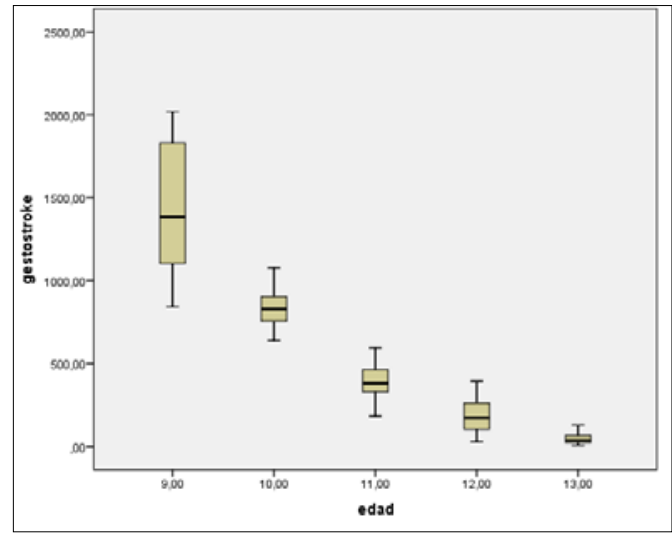

Gráfico 5. Distancia temporal en milisegundos entre el inicio del golpe de gesto e inicio de la producción vocal.

\section{3. ¿Cómo se correlacionan cronológicamente las vocalizaciones con las funciones vocálicas?}

En este caso se tuvieron en cuenta los 933 actos comunicativos que fueron clasificados como actos comunicativos con vocalización (723 en los que solo se producía vocalización y los 210 en los que la vocalización se acompañaba de gesto). Además, hay que señalar que del total de 933 vocalizaciones en $110(11,8 \%)$ resultó imposible establecer la función de ellas por falta de indicios contextuales, aunque sí se pudo determinar que se dirigían a un interlocutor por los indicios de intencionalidad y, en ese sentido, eran comunicativas.

En relación con la cuestión planteada, es decir, qué tipo de función se asocia a la vocalización empleada por el niño en cada subgrupo de edad, la Tabla 6 muestra la distribución correspondiente a la función vocálica para todos los subgrupos de edad. Los resultados muestran que la función emotiva es la predominante en los dos primeros subgrupos de edad, con un $53,37 \%$ y un $43,47 \%$ respectivamente. A partir del subgrupo 0;11 la proporción se invierte, así el 45,55\% lo constituirían las funciones declarativa e imperativa, mientras que la asignación de la función expresiva descendería hasta un $23,55 \%$. Esta tendencia continua en los subgrupos $1 ; 0$ y $1 ; 1$, en los que la función declarativa e imperativa son mayoritarias frente al resto de funciones. La función emotiva continua descendiendo hasta ser superada en el subgrupo $1 ; 1$ por la función fática con un $18,07 \%$ frente al $16,86 \%$ de la función emotiva. La evolución de esta función fática paralela al desarrollo cronológico evidenciaría una comprensión del diálogo como construcción cooperativa en la que prima la interacción, más allá de la capacidad para producir un enunciado de respuesta verdaderamente relevante. Podríamos incluso intuir aquí el funcionamiento del principio de cooperación de Grice (1975), en tanto la conducta del niño parece revelar la conciencia de que, ante ciertos enunciados del adulto, él se encuentra obligado a cooperar produciendo, a su vez, una emisión vocal en respuesta. Esta circunstancia se 
ve avalada por el aumento porcentual que se produce en las funciones mímica y guía de acción, como funciones significativas del interés del niño de participar y permanecer en la interacción con el adulto.

En el Gráfico 6, se muestra este aumento porcentual y paralelo a la edad que se produce en las funciones imperativa y fática. Esta circunstancia se observa también en el gráfico de correspondencias entre la tipología gestual y la función vocálica que hemos realizado en el Gráfico 6. De hecho, el aumento es constante, produciéndose picos porcentuales concentrados en los subgrupos 0;11 y 1;0. Esta circunstancia es interesante ya que el balbuceo conversacional es propiamente una proto-conversación donde, a pesar de no haber referencialidad, ciertamente existe una fuerza perlocutiva e ilocutiva que origina en el niño la habilidad creciente para pedir y seguir turnos alternativos en esa proto-conversación.

Tabla 6. Número total y porcentual de la función vocálica en cada subgrupo de edad.

\begin{tabular}{|c|c|c|c|c|c|c|c|c|c|c|c|c|}
\hline \multirow{2}{*}{ Edad } & \multicolumn{2}{|c|}{ Declarativa } & \multicolumn{2}{|c|}{ Imperativa } & \multicolumn{2}{c|}{ Emotiva } & \multicolumn{2}{c|}{ Mímica } & \multicolumn{2}{|c|}{ Guía de acción } & \multicolumn{2}{|c|}{ Fática } \\
\cline { 2 - 15 } & $N$ & $\%$ & $N$ & $\%$ & $N$ & $\%$ & $N$ & $\%$ & $N$ & $\%$ & $N$ & $\%$ \\
\hline $0 ; 9$ & 26 & 17,56 & 17 & 11,48 & 79 & 53,37 & 9 & 6,08 & 13 & 8,78 & 4 & 2,70 \\
\hline $0 ; 10$ & 39 & 21,19 & 25 & 13,58 & 80 & 43,47 & 12 & 6,52 & 19 & 10,32 & 9 & 4,89 \\
\hline $0 ; 11$ & 72 & 27,79 & 46 & 17,76 & 61 & 23,55 & 26 & 10,03 & 32 & 12,35 & 22 & 8,49 \\
\hline $1 ; 0$ & 39 & 26,17 & 31 & 20,80 & 28 & 18,79 & 11 & 7,38 & 19 & 12,75 & 21 & 14,09 \\
\hline $1 ; 1$ & 18 & 21,68 & 22 & 26,50 & 14 & 16,86 & 6 & 7,22 & 8 & 9,63 & 15 & 18,07 \\
\hline
\end{tabular}
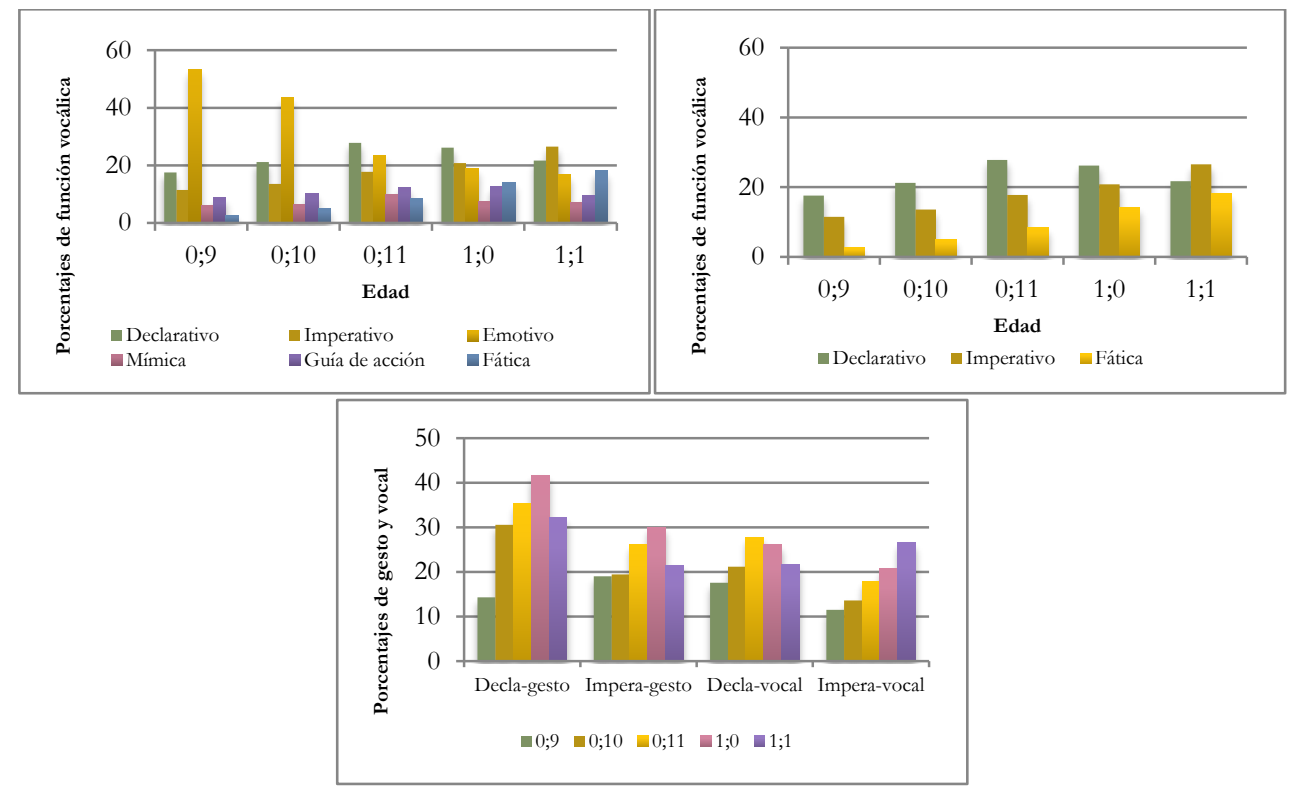

Gráfico 6. Ratio de porcentajes correspondientes a las funciones vocálicas (gráfico superior izquierda). Ratio de porcentajes correspondientes a las funciones declarativa, imperativa y fática (gráfico superior derecha). Comparativa porcentual entre la tipología gestual declarativa e imperativa y su correspondencia en las funciones vocálicas (gráfico inferior central). 


\section{Discusión y conclusiones}

Este estudio pretende realizar su aportación a la literatura que investiga el desarrollo de las combinaciones gesto y vocalizaciones tempranas en bebés. Trabajos anteriores ya han señalado la temprana conexión entre la rítmica motora y los movimientos vocálicos, como un elemento precursor en la futura coordinación en los adultos entre gesto y habla (Ejiri \& Masataka, 2001). Sin embargo, pocos estudios han investigado el modelo específico que se desarrolla en la coordinación temprana de gestos comunicativos y vocalizaciones tempranas. Para nuestro conocimiento, tan solo hay dos trabajos que analizan esta cuestión: la investigación de Butcher y GoldinMeadow (2000), quienes sugieren que los niños comienzan a combinar las dos modalidades en el periodo de una sola palabra, pero no se produce hasta el comienzo del período lingüístico de dos palabras, cuando los niños integran el gesto y el discurso como un solo sistema para comunicarse intencionadamente; y por otra parte, el trabajo de Esteve-Gibert y Prieto (2014), que analiza las combinaciones de gestovocalización ya en la etapa del balbuceo, y estudia la prominencia prosódica en el gesto deíctico, atendiendo a las conclusiones recientes sobre el modo en el que el gesto y el discurso se coordinan temporalmente en el lenguaje adulto.

Creemos que las limitaciones que presenta el estudio respecto al número de informantes se pueden compensar atendiendo al importante número de datos obtenidos. En este punto, hay que subrayar que se describen casi 6 horas de grabación con un cómputo total de 1260 actos comunicativos. Por tanto, si se atiende a las conclusiones recientes y descritas en la literatura sobre la coordinación temporal entre gesto y vocalizaciones para etapas tempranas en el desarrollo prelingüístico y, teniendo en cuenta los tres objetivos planteados inicialmente, podemos también afirmar que nuestros resultados presentan la siguiente interpretación. En primer lugar, los dos niños analizados no producen unidades léxicas definidas, sino que nos encontramos ante las producciones típicas del balbuceo canónico, reduplicativo y variado protoconversacional.

En segundo lugar, en todos los subgrupos cronológicos analizados el gesto se inicia antes que la vocalización, mostrando un patrón similar a lo que ocurre en los adultos (Butterworth \& Beattie, 1978; Levelt et al., 1985; Nobe, 1996; De Ruiter, 1998; Krahmer \& Swerts, 2007; Loehr, 2007; Ferré, 2010; Leonard \& Cummins, 2010; Roustan \& Dohen, 2010; Bergmann et al., 2011; Esteve-Gibert \& Prieto, 2013). Ahora bien, la combinación gesto-vocalización es estadísticamente significativa a partir del subgrupo $1 ; 0$, en el que los niños comienzan a producir sus vocalizaciones combinadas con el gesto con más frecuencia que la producción sola de gestos. Por tanto, podemos entender que esta combinación empieza a ser coordinada con un propósito intencional en la etapa prelingüística del balbuceo variado. Estos resultados confirman los análisis de Butcher y Goldin-Meadow (2000) y Esteve-Gibert y Prieto (2014), y adelantan a la etapa del balbuceo variado la coordinación multimodal entre 
gestos y vocalizaciones. Por tanto, esta intención comunicativa del niño se refleja ya en este periodo prelingüístico, y aunque no se han encontrado unidades léxicas, el análisis de la tipología gestual y de las funciones vocálicas indica que esta coordinación tiene un propósito intencional comunicativo.

En tercer lugar, en esta coordinación temporal la prominencia de los gestos deícticos (señalar y alcanzar) resulta fundamental, ya que se constata a partir del subgrupo 0;10 una presencia mayoritaria de este tipo gestual frente a otros también analizados (emotivo, convencional y simbólico). Por tanto, hay que realizar una lectura independiente respecto a la tipología gestual simbólica, ya que a tenor de los datos recogidos, la evolución gestual no sigue el patrón normal de aumento en la utilización de este tipo de gesto paralelamente al incremento de la edad, tal y como se constata en estudios similares centrados en la gestualización simbólica (Acredolo \& Goodwin, 2001).

En cuarto lugar, la motivación gestual prominente es la declarativa frente a la motivación imperativa en todos los subgrupos de edad, aunque con una clara significación en la que la motivación imperativa se transmite mediante el gesto deíctico de alcanzar y la motivación declarativa mediante el gesto deíctico de señalar. Además, en este punto hay que destacar que los resultados estadísticos mediante la aplicación del Modelo Lineal Mixto avalaron la hipótesis de la coordinación temporal entre el gesto deíctico de señalar y alcanzar con una motivación imperativa y la producción vocal, ya que en estos casos el gesto deíctico necesitaba de más tiempo para su ejecución, con lo que se podría coordinar de una manera más adecuada con la vocalización. Estos resultados confirman los datos aportados por otros trabajos previos en este campo (Cochet \& Vauclair, 2010; Colonnesi, Stams, Koster \& Noom, 2010; Esteve-Gibert \& Prieto, 2014). Además, hay que señalar a este respecto que atendiendo al procedimiento metodológico de grabación, la tipología de gestos registrada es la resultante de las variadas acciones cotidianas que desarrolla el niño en casa con su interlocutor. Por tanto, hay que descartar posibles sesgos propiciados por contextos específicos de grabación, en los que los niños tan solo son investigados bajo la premisa del juego libre, por ejemplo.

En quinto lugar, hay que señalar que a partir del subgrupo 0;11 las funciones vocálicas imperativas y declarativas son las mayoritarias. El aumento de estas funciones paralelamente a la edad -también descritas para la tipología gestual- junto con un creciente uso de la función fática nos lleva a realizar una lectura en la que se destaca la existencia de una habilidad creciente en el niño para pedir y seguir turnos alternativos en esa proto-conversación. Es en esta etapa en la que el significado señalado ya no se limita a indicar o señalar cuál es su estado, sino que comunica, y por tanto, hay una referencia hacia el significado simbólico (Vázquez, Alonso, Prego \& Sanromán, 2002). 
Y por último, hay una clara evidencia en la coordinación temporal entre el gesto deíctico y la vocalización ya en la etapa del balbuceo variado o proto-conversacional. Así, hay dos elementos en los que se basa esta afirmación: el inicio del gesto es anterior al inicio de la vocalización en todos los subgrupos de edad y el inicio del golpe de gesto se coordina temporalmente con el inicio del habla. En primer lugar, los resultados revelan ya para el subgrupo 0;11 un patrón similar al adulto en la correlación que se produce en la distancia entre el inicio del gesto y la producción vocal. Además, hay que señalar que en el análisis estadístico se manifiesta que la edad del niño afecta significativamente a la medida en esta distancia, debido a que en el subgrupo 0;9 la distancia entre esas dos medidas es significativamente mayor que en el subgrupo 1;1. En segundo lugar, los resultados indican también que a medida que avanza el subgrupo de edad se reduce la distancia entre el inicio de la vocalización y el inicio del golpe de gesto, llegando en el subgrupo 1;1 a una coordinación casi simultánea. Estos datos se han visto corroborados desde un punto de vista estadístico, ya que nuevamente la edad del niño afecta significativamente a la medida de esta distancia. Por tanto, el subgrupo $1 ; 1$ es el que se presenta estadísticamente significativo, y que corresponde con el momento en el que el niño comienza con la producción de combinaciones de sílabas repetidas. Estos datos confirman los resultados aportados por otros estudios en este campo, y sugieren ya una coordinación temporal entre el gesto comunicativo y el discurso en las primeras etapas de la producción del lenguaje. Sin embargo, somos conscientes de las limitaciones de este estudio longitudinal sobre 1260 actos comunicativos entre dos niños en un contexto de observación natural libre. Así, en investigaciones futuras (1) se debería incrementar este número de informantes con el objeto de afianzar nuestra afirmación de que el gesto y la vocalización se coordinan temporalmente ya en el inicio de la producción prelingüística; (2) se deberían de analizar las funciones comunicativas tempranas con el objeto de observar si hay una diferenciación en las mismas ateniendo a su contorno entonativo final. 


\section{REFERENCIAS BIBLIOGRÁFICAS}

Acredolo, L. \& Goodwin, S. (2001). Los gestos del bebé. Barcelona: Oniro.

Bates, E., Camaioni, L. \& Volterra, V. (1975). The acquisition of performatives prior to speech. Merrill-Palmer Quarterly of Behavior and Development, 21, 205-224.

Bergmann, K., Aksu, V. \& Kopp, S. (2011). The relation of speech and gestures: Temporal Synchrony Follows Semantic Synchrony. Ponencia presentada en el 2nd Workshop on Gesture and Speech in Interaction, Bielefeld, Alemania.

Blake, J., Vitale, G., Osborne, P. \& Olshansky, E. (2005). A cross-cultural comparison of communicative gestures in human infants during the transition to language. Gesture, 5, 201-217.

Bloom, P. (1993). Language acquisition. Core readings. Cambridge: Harvester Wheatsheaf.

Bosh, L. (2004). Evaluación fonológica del habla infantil. Barcelona: Masson.

Bruner, J. (1975). From communication to language. Cognition, 3, 255-287.

Butcher, C. \& Goldin-Meadow, S. (2000). Gesture and the transition from one- to two-word speech: When hand and mouth come together. En D. McNeill (Ed.), Language and Gesture (pp. 235-258). Nueva York: Cambridge University Press.

Butterworth, B. \& Beattie, G. (1978). Gesture and silence as indicators of planning in speech. En R. Campbell \& G. T. Smith (Eds.), Recent advances in the psychology of language: Formal and experimental approaches (pp. 347-360). Nueva York: Plenum Press.

Capone, N. C. \& McGregor, K. K. (2004). Gesture development: A review for clinicians and researchers. Journal of Speech, Language, and Hearing Research, 47, 173-186.

Cochet, H. \& Vauclair, J. (2010). Pointing gesture in young children: Hand preference and language development. Gesture, 10, 129-149.

Cohen, J. (1960). A coefficient of agreement for nominal scales. Educational and Psychological Measurement, 20(1), 37-46.

Colonnesi, C., Stams, G. J. J. M., Koster, I. \& Noom, M. J. (2010). The relationship between pointing gesture and language: A meta-analysis. Developmental Review, 30, 352-366.

De Ruiter, J. P. (1998). Gesture and speech production. Tesis doctoral, Universidad de Nijmegen, Nijmegen, Países Bajos. 
De Ruiter, J. P., (2000). The production of gesture and speech. En D. McNeill (Ed.), Language and Gesture (pp. 284-311). Cambridge: Cambridge University Press.

Ejiri, K. \& Masataka, N. (2001). Co-occurrence of preverbal vocal behavior and motor action in early infancy. Developmental Science, 4, 40-48.

Ekman, P. \& Friesen, W. (1969). The repertoire of nonverbal behavioural categories: Origins, usage and coding. Semiotica, 1, 49-98.

Esteve-Gibert, N. \& Prieto, P. (2013). Intonational and gestural structures are temporally coordinated. Laboratory Phonology (LabPhon 13). Stuttgart (Alemania), July 27-29 [en línea]. Disponible en: http://dx.doi.org/10.1044/1092-4388(2012/12-0049.)

Esteve-Gibert, N. \& Prieto P. (2014). Infants temporally coordinate gesture-speech combinations before they produce their first words. Speech Communication, 57, 301-316.

Esteve-Gibert, N., Prieto, P. \& Pons, F. (2015). Nine-month-old infants are sensitive to the temporal alignment of prosodic and gesture prominences. Infant Behavior and Development, 38, 126-129.

Feldman, R. \& Reznick, J. S. (1996). Maternal perception of infant intentionality at 4 and 8 months. Infant Behavior and Development, 19, 483-496.

Fernández, I. (2009). ¿Cómo hablan los niños? El desarrollo del componente fonológico en el lenguaje infantil. Madrid: Arco/Libros.

Ferré, G. (2010). Timing relationships between speech and co-verbal gestures in spontaneous French. En Proceedings of Language Resources and Evaluation, Workshop on Multimodal Corpora, pp. 86-91.

Goldin-Meadow, S. (2005). The two faces of gesture: Language and thought. Gesture, $5,241-257$.

Goldstein, B. A. \& Pollock, K. E. (2000). Vowel errors in Spanish-speaking children with phonological disorders: A retrospective, comparative study. Clinical Linguistics and Phonetics, 14, 217-225.

Grice, H. P. (1975). Logic and conversation. En P. Cole \& J. L. Morgan (Eds.), Syntax and Semantics (pp. 41-58). Nueva York: Academic Press.

Halliday, M.A.K. (1975). Learning how to mean. Londres: Edward Arnold.

Igualada, A., Bosch, L. \& Prieto P. (2015). Language development at 18 months is related tomultimodal communicative strategies at 12 months. Infant Behavior and Development, 39, 42-52. 
Iverson, J. M. (2010). Multimodality in infancy: Vocal-motor and speech-gesture coordinations in typical and atypical development. Enfance, 2010(3), 257-274.

Iverson, J. M. \& Thelen, E. (1999). Hand, mouth and brain: The dynamic emergence of speech and gesture. Journal of Consciousness Studies, 6, 19-40

Iverson, J. M., Tencer, H. L., Lany, J. \& Goldin-Meadow, S. (2000). The relation between gesture and speech in congenitally blind and sighted languagelearners. Journal of Nonverbal Behavior, 24, 105-130.

Iverson, J. M. \& Goldin-Meadow, S. (2005). Gesture paves the way for language development. Psychological Science, 16, 367-371.

Jiménez Bravo-Bonilla, M. (2013). Entre el gesto y la palabra: Contribuciones de la neurolingüística al principio de paridad. Estudios Interlingüísticos, 1, 47-65.

Karousou, A. (2003). Análisis de las vocalizaciones tempranas: Su patrón evolutivo y su función determinante en la emergencia de la palabra. Tesis doctoral, Universidad Complutense, Madrid, España.

Kaye, K. (1982). The mental and social life of babies. Chicago: The University of Chicago Press.

Kendon, A. (1980). Gesticulation and speech: Two aspects of the process of utterance. En M. R. Key (Ed.), The Relationship of Verbal and Nonverbal Communication (pp. 207-227). The Hague: Mouton.

Kendon, A. (2004). Gesture: Visible action as utterance. Cambridge: Cambridge University Press.

Kita, S. (2000). How representational gestures help speaking. En D. McNeill (Ed.), Language and Gesture (pp. 162-185). Cambridge: Cambridge University Press.

Krahmer, E. \& Swerts, M. (2007). The effects of visual beats on prosodic prominence: Acoustic analyses, auditory perception and visual perception. Journal of Memory and Language, 57(3), 396-414.

Lausberg, H. \& Sloetjes, H. (2009). Coding gestural behavior with the NEUROGESELAN system. Behavior Research Methods, 41(3), 841-849.

Leonard, T. \& Cummins, F. (2010). The temporal relation between beat gestures and speech. Language and Cognitive Processes, 26, 1295-1309.

Levelt, W. J., Richardson, G. \& La Heij, W. (1985). Pointing and voicing in deictic expressions. Journal of Memory and Language, 24, 133-164. 
Lew, A. \& Butterworth, G. (1997). The development of hand-mouth coor-dination in 2 - to 5-month-old infants: Similarities with reaching and grasping. Infant Behavior and Development, 20, 59-69.

Liszkowski, U. (2007). Human twelve-months-olds point cooperatively to share interest with and helpfully provide information for a communicative partner. En K. Liebal, C. Müller \& S. Pieka (Eds.), Gestural Communication in Nonbuman and Human Primates (pp. 124-140). Ámsterdam: John Benjamins.

Loehr, D. (2007). Aspects of rhythm in gesture and speech. Gesture, 7, 179-214.

López Ornat, S. \& Karousou, A. (2005). Las vocalizaciones tempranas (8-30 meses) y su relación con el vocabulario y la gramática. Su medida en el CDI-Español: Resultados preliminares. En M. A. Mayor Cinca, B. Zubiauz de Pedro \& E. Díez-Viñaloria (Eds.), Estudios sobre la adquisición del lenguaje (pp. 401-420). Salamanca: Universidad de Salamanca.

MacNeill, D. (1992). Hand and mind what gestures reveal about thought. Chicago: University of Chicago Press.

Miller, J. L. \& Lossia, A. K. (2013). Prelinguistic infants' communicative system: Role of caregiver social feedback. First Language, 33, 524-544.

Mundy P. \& Gomes, A. (1998). Individual differences in joint attention skill development in the second year. Infant Behavior and Development, 21, 468-482.

Nobe, S. (1996). Representational gestures, cognitive rbythms, and acoustic aspects of speech: a network/threshold model of gesture production. Tesis doctoral, Universidad de Chicago, Chicago, USA.

Oller, D.K. (2000). The emergence of the speech capacity. Mahwah, N.J.: Lawrence Erlbaum Associates.

Oller, D. K., Wieman, L .A., Doyle, W. J. \& Ross, C. (1976). Infant babbling and speech. Journal of Child Language, 3, 1-11.

Papaeliou, C. \& Trevarthen, C. (2006). Prelinguistic pitch patterns expressing ‘communication' and 'apprehension'. Journal of Child Language, 3(3), 163-178.

Piaget, J. (1936). La naissance de l'intelligence chez l'enfant. Neuchâtel: Délachaux et Niestlé. Traducción castellano, Madrid, Aguilar, 1969.

Rivero, M. (2003). Los inicios de la comunicación: La intencionalidad comunicativa y el significado como procesos graduales. Anuario de Psicología, 34(3), 337-356.

Rochat, P. (2007). Intentional action arises from early reciprocal exchanges. Acta Psychologica, 124, 8-25. 
Romero, A., Etxebarria, A., Gaminde, I. \& Garay, U. (2015). El papel de la prosodia en la enseñanza de la L1. Un aporte didáctico para el aula de Educación Infantil y de Educación Primaria. Revista Phonica, 11. (en prensa).

Roustan, B. \& Dohen, M. (2010). Co-production of contrastive prosodic focus and manual gestures: Temporal coordination and effects on the acoustic and articulatory correlates of focus. En Proceeding of the Speech Prosody, Chicago.

Rowe, M. \& Goldin-Meadow, S. (2009). Differences in early gesture explain SES disparities in child vocabulary size at school entry. Science, 323, 951-953.

Sacks, J. (1997). Communication development in infancy. En J. Berko-Gleason (Ed.), The development of Language. Needham Heights: Allyn y Bacon.

Sarriá, E. (1991). Observación de la comunicación intencional preverbal: Un sistema de codificación basado en el concepto de la categoría natural. Psicotema, 3, 359380 .

Shore, C., Bates, E., Bretherton, I., Beeghly, M. \& O’Connell, B. (1990). Vocal and gestural symbols: Similarities and differences from 13 to 28 months. En V. Volterra \& C. J. Erting (Eds.), From Gesture to Language in Hearing and Deaf Children (pp. 211-236). Nueva York: Springer-Verlag.

Trevarthen, C. (1979). Communication and cooperation in early infancy: A description of primary intersubjectivity. En M. Bullowa (Ed.), Before the speech: The beginning of interpersonal communication (pp. 321-347). Cambrigde: Cambrigde University Press.

Thelen, E. (1992). Development as a dynamic system. Current directions. Psychological Science, 1, 189-193.

Tomasello, M. (1988). The role of joint attentional process in early language development. Language Sciences, 10, 69-88.

Tomasello, M., Carpenter, M. \& Liszkowski, U. (2007). A new look at infant pointing. Child Development, 78, 705-722.

Tomasello, M. \& Farrar, J. (1986). Joint attention and early language. Child Development, 57(6), 1454-1463.

Triadó, C. (1984). Algunos aspectos del lenguaje del niño en su función comunicativa. En M. Siguán (Comp.), Estudios sobre psicología del lenguaje infantil (pp. 232-248). Madrid: Pirámide. 
Vázquez, N., Alonso, M., Prego, M. \& Sanromán, B. (2002). Unidades léxicas no descriptivas: Un puente entre la lexicografía y la pragmática. En J. I. Pérez \& M. Campos (Eds.), Cuestiones de lexicografía (pp. 235-247). Madrid: Tris Tram.

Vihman, M. M. (1996). Phonological development: The origins of language in child. Oxford, UK: Blackwell Publishers.

Volterra, V., Camaioni, L., Benigni, L. \& Bates, E. (1981). Le prime parole. Giornale Italiano di Psicología, 8, 243-263.

Vygotsky, L. (1979). Internalización de las funciones psicológicas superiores. Barcelona: Crítica.

West, B., Welch, K. B. \& Galecki, A. T. (2007). Linear mixed models: A practical guide using statistical software. Nueva York: Chapman \& Hall/CRC.

\section{NOTAS}

${ }^{1}$ Esta investigación se ha llevado a cabo gracias a la subvención del proyecto GIU 13/23.

2 Para un análisis de las diferentes teorías, ver Jiménez Bravo-Bonilla (2013).

${ }^{3}$ La cuarta y quinta línea la hemos interpretado como un único momento, ya que la realización del ápex está condicionada por la fase de golpe gestual o stroke.

4 En palabras de Kendon (2004: 112): “the phase when the 'expression' of the gesture, whatever it may be, is accomplished and in which the movement dynamics of 'effort' and 'shape' are expressed with greater clarity'.

${ }^{5}$ Esta anotación no fue sencilla ya que en algunas ocasiones no se logra conseguir una imagen estática para señalar la fase en cuestión (golpe o pico gestual), ni aún con la utilización de herramientas que nos proporciona ELAN de avanzar o retroceder en el pixelado de la imagen. Por tanto, en estos casos se ha utilizado el último de los fotogramas para marcar el hito en la duración de la fase. En la Figura 2 se resume el procedimiento seguido para la codificación del gesto y se muestra un ejemplo para cada fase gestual.

${ }^{6}$ El infrecuente contenido segmental de las vocalizaciones y su complejidad prosódica las hacen difíciles de transcribir, codificar y medir. Actualmente, diversos investigadores (Vihman, 1996; Oller, 2000; Karousou, 2003) se afanan en desarrollar sistemas de codificación fiables que puedan simplificar y agilizar el registro y análisis de datos de la actividad vocal anterior a las primeras palabras.

${ }^{7} \mathrm{La}$ fórmula empleada con SPSS para el cálculo de los valores fue la siguiente: MIXED gesto BY edad WITH informante /CRITERIA=CIN(95) MXITER(100) MXSTEP(10) SCORING(1) SINGULAR(0.000000000001) HCONVERGE(0, ABSOLUTE) LCONVERGE(0, ABSOLUTE) PCONVERGE(0.000001, ABSOLUTE) /FIXED= age | 
SSTYPE(3) /METHOD=REML /PRINT=DESCRIPTIVES G SOLUTION TESTCOV / RANDOM INTERCEPT I SUBJECT (subject) COVTYPE(CV) /EMMEANS = TABLES(age) COMPARE ADJ(LSD).

8 Por tanto, los modelos lineales mixtos permiten analizar este tipo de datos, modelando, por un lado, la evolución de la respuesta promedio en función del tiempo y otras covariables mediante efectos fijos (estructura media) y, por otro lado, la variabilidad entre las medidas repetidas dentro y entre sujetos por medio del error y los efectos aleatorios (estructura de covariancia).

${ }^{9}$ Se ha empleado el término subgrupo para en correspondencia a cada uno de los cinco tramos de mes analizado en los dos niños $(0 ; 9,0 ; 10,0 ; 11,1 ; 0$ y $1 ; 1)$.

\section{* AGRADECIMIENTOS}

Esta investigación se ha realizado dentro del proyecto IT1028/16 subvencionado por el Gobierno Vasco y del proyecto GIU 16/22 subvencionado por la Universidad del País Vasco/Euskal Herriko Unibertsitatea. 